\title{
Association Between Low Serum Vitamin D Levels and Sepsis: A Single-Center Study in Tehran, Iran
}

\author{
Masume Bayat ${ }^{1}$, Latif Gachkar ${ }^{2}$, Mahya Zahirnia ${ }^{2}$ and Fahimeh Hadavand ${ }^{2,{ }^{*}}$ \\ ${ }^{1}$ Physical Medicine and Rehabilitation Research Center, Shahid Beheshti University of Medical Sciences, Tehran, Iran \\ ${ }^{2}$ Infectious Diseases and Tropical Medicine Research Center, Shahid Beheshti University of Medical Sciences, Tehran, Iran \\ "Corresponding author: Infectious Diseases and Tropical Medicine Research Center, Shahid Beheshti University of Medical Sciences, Tehran, Iran. Email: \\ fahimehadavand140@gmail.com
}

Received 2020 April 01; Revised 2021 February 22; Accepted 2021 April 11.

\begin{abstract}
Background: Vitamin D insufficiency is common in critically ill patients. It is hypothesized that vitamin D deficiency would be associated with sepsis in the critically ill. Thus, the present study aimed to investigate the association between vitamin $\mathrm{D}$ and sepsis severity.

Method: In this cross-sectional study, patients with sepsis referring to a university hospital in Tehran, Iran, from February 2018 to March 2019 were included. Plasma concentrations of vitamin D in critically ill subjects admitted were assessed. Data were analyzed using SPSS version 20.0. P-values less than 0.05 were considered statistically significant.

Results: Among the investigated patients, the mean serum level of vitamin D3 was $19.03 \pm 13.08 \mathrm{ng} / \mathrm{mL}$. The prevalence of vitamin $\mathrm{D}$ insufficiency in critically ill subjects with sepsis was 100\% (150/150). Only sex $(\mathrm{P}=0.01)$ indicated a significant association with vitamin D. Patients suffering from severe sepsis had lower levels of vitamin D compared to the patients with non-severe sepsis $(\mathrm{P}=$ 0.07).

Conclusions: The present study showed that all critically ill patients studied had vitamin D insufficiency. In line with the biological evidence, the present study suggests that vitamin D deficiency may predispose patients to sepsis. Further studies are needed to establish the causes and mechanisms underlying these interpretations.
\end{abstract}

Keywords: Sepsis, Vitamin D deficiency, Iran

\section{Background}

Sepsis is common among critically ill patients and is associated with significant mortality and morbidity $(1,2)$. Despite advances in clinical care and outcomes, existing epidemiologic studies suggest that sepsis remains a major health problem worldwide $(3,4)$. In 2017 , more than 11 million sepsis-related deaths were reported, representing $19.7 \%$ of all global deaths (5). Sepsis is treatable, and infection-prevention efforts can reduce sepsis incidence and improve outcomes (6-8). Recently, it has been found that vitamin D supplements can improve prognosis in patients with sepsis $(9,10)$. Vitamin D plays an essential role in both the adaptive and innate immune systems for the ideal function of antimicrobial activity (11-13). Thus, it is a contributing factor to decreased sepsis incidence and severity (13). However, patients with severe infections, such as those withsepsis, usually have a high rate of vitamin D insufficiency (14-16). Furthermore, several studies on patients with sepsis have shown strong associations between decreased vitamin D levels and adverse outcomes (i.e. in- creased length of stay, acute kidney injury, and mortality) (17-19). Although the role of vitamin D in sepsis has been previously suggested, the association of vitamin D with increased morbidity and mortality has not yet been established (20-22). In Iran, a high proportion of vitamin D deficiency was observed in the general population (23). There is also an increasing number of patients with sepsis in healthcare settings (24).

\section{Objectives}

This study aimed to find the relationship between vitamin D levels and outcomes among patients with sepsis in Tehran, Iran.

\section{Method}

\subsection{Settings and Patients}

This cross-sectional study was conducted at a university hospital (Imam Hossein Hospital) in Tehran, Iran, from 
1 February 2018 to 5 March 2019. Patients greater than 18 years old were included if they met the following criteria for sepsis: (1) Confirmed or suspected source of infection determined by the treating clinician and (2) having two or more criteria for the systemic inflammatory response syndrome (SIRS) (25). Patients were excluded if they experienced shock due to reasons other than sepsis, had neuroendocrine diseases, were in cardiac arrest on arrival, suffered from mental disorders, were under constant use of vitamin $\mathrm{D}$, or were pregnant. Patient data, including demographics, comorbidities, and laboratories such as cultures and the suspected source of infection, were obtained through enrollment. The institutional human subjects committee approved the current study (IR.SBMU.MSP.REC.1397.126), and informed consent was obtained from the patients.

\subsection{Vitamin D Status Measurements}

Whole blood collected was placed into the tubes containing ethylenediaminetetraacetic acid as an anticoagulant. Within 1 hour of collection, each sample was centrifuged at $1500 \mathrm{rpm}$ for 10 minutes. The plasma was directly aliquoted and stored at $-20^{\circ} \mathrm{C}$. After completion of samples, the concentration of serum 25-hydroxy vitamin D3 was measured by enzyme-linked immunosorbent assay (ELISA) (Immunoassays S.A., Belgium) according to the manufacturer's protocol. Vitamin D deficiency was defined as baseline serum 25-hydroxyvitamin D (25OHD) levels $<30 \mathrm{ng} / \mathrm{mL}$ (26).

\subsection{Statistical Analysis}

SPSS version 20.0 (IBM Corp., Armonk, NY, USA) was used for data analysis. Categorical and continuous variables were analyzed using the chi-square test, t-test, and analysis of variance (ANOVA). P-values less than 0.05 were considered statistically significant.

\section{Results}

A total of 150 patients with a mean age of $70.8 \pm 13.3$ years were studied (males $=96(64.0 \%)$ and females $=54$ (36.0\%)). In the studied patients, the mean serum level of vitamin D3 was $19.03 \pm 13.08 \mathrm{ng} / \mathrm{ml}$. If the serum levels of vitamin D3 were $<30 \mathrm{ng} / \mathrm{mL}$, vitamin D deficiency was confirmed. Thus, the prevalence of vitamin D insufficiency in critically ill subjects with sepsis was 100\% (150/150). Table 1 indicates the relationship between different variables and the mean serum level of vitamin D. Only sex $(P=0.01)$ showed a significant association with the mean serum level of vitamin $\mathrm{D}$.

The cases included 56 patients with non-severe sepsis, 26 with severe sepsis, and 68 with septic shock. The mean age of patients with septic shock was not statistically different from the other two groups. Likewise, the number of patients with underlying diseases in the septic shock group was comparable to those in other groups. Patients suffering from severe septic had lower levels of vitamin D compared to those with non-severe sepsis $(\mathrm{P}=0.07)$.

\section{Discussion}

The present study indicated a high rate of vitamin D deficiency in critically ill patients. Although there were different cut-off points for the definition of vitamin D insufficiency, previous reports presented a high rate of vitamin D deficiency in patients with sepsis. In 2015, Alves and others reported that $98 \%$ of patients with sepsis had severe vitamin D deficiency (27). Likewise, a subsequent investigation by Shojaei et al. found that the median concentrations of vitamin D levels in patients with sepsis were $19 \mathrm{ng} / \mathrm{mL}$, similar to the concentrations found in our study (24). Jeng and colleagues found significant differences in vitamin D concentrations in patients with sepsis in the intensive care unit compared to healthy individuals (13).

The results of previous studies revealed that vitamin D insufficiency in patients with sepsis was considerably associated with increased mortality $(28,29)$. The potential mechanisms for the observed investigation may be related to (1) the stimulatory effects of vitamin D on innate immunity, (2) the suppression of immune regulators, and (3) the negative effects on pathways serving to reduce potential inflammatory damage (26, 30-32).

Previous studies showed that vitamin D deficiency might increase the risk of bacterial and viral infections. Accordingly, in a randomized, placebo-controlled trial, patients with pulmonary tuberculosis who received vitamin $\mathrm{D}$ in their regimen showed a significant difference in sputum conversion compared to the control group (33). The evidence also proposed that vitamin D might act against influenza and invasive pneumococcal disease $(34,35)$.

Since vitamin D status plays an important role in the pathogenesis of sepsis and other critical diseases, limited treatment options exist to address this issue. The American Society for Parenteral and Enteral Nutrition (ASPEN) recommends 200 IU vitamin D daily for hospitalized patients (36). However, further investigations have estimated that doses of 400 or 500 IU daily remained in the insufficient range for most hospitalized patients $(14,37)$. Thus, these findings recommend that higher doses of vitamin $\mathrm{D}$ are likely needed to be used in patients with sepsis to correct vitamin D insufficiency.

There is some limitation to the current study. Due to the limited data obtained, we were unable to provide details on acute or chronic liver failure, premorbid health status, type of infection, use of vitamin D supplements, and 


\begin{tabular}{|c|c|c|c|}
\hline Variable & No. (\%) & Vitamin D3 & P-Value \\
\hline Sex & & & 0.01 \\
\hline Male & $96(64.0)$ & 18 & \\
\hline Female & $54(36.0)$ & 19 & \\
\hline Age (year) & & & 0.12 \\
\hline$<65$ & $76(50.6)$ & 14 & \\
\hline$\geq 65$ & $74(50.3)$ & 20 & \\
\hline Source of infection & & & 0.14 \\
\hline Pneumonia & $48(32.0)$ & 20 & \\
\hline Soft tissue infection & $41(27.3)$ & 14 & \\
\hline Bacteremia & $22(14.7)$ & 16 & \\
\hline Urinary tract infection & $20(13.3)$ & 11 & \\
\hline Central nervous infection & $4(2.6)$ & 22 & \\
\hline Gastrointestinal infection & $2(1.3)$ & 7.6 & \\
\hline Others & $13(8.7)$ & 11 & \\
\hline Type of sepsis & & & 0.07 \\
\hline Non-severe Sepsis & $56(37.3)$ & 18 & \\
\hline Severe Sepsis & $26(16.7)$ & 9 & \\
\hline Septic Shock & $68(46.0)$ & 13 & \\
\hline
\end{tabular}

data on the outcomes. Further studies are required to evaluate the effects of other potential medical comorbidities.

In conclusion, the present study indicated that critically ill patients had vitamin D insufficiency. In line with the biological evidence, we suggest that vitamin D deficiency may predispose patients to sepsis. It seems that the consumption of vitamin D supplements may help decrease the prevalence of sepsis. Further studies are needed to confirm the results and establish the causes and mechanisms underlying these observations.

\section{Acknowledgments}

This study was supported by Shahid Beheshti University of Medical Sciences, Tehran, Iran.

\section{Footnotes}

Authors' Contribution: All authors contributed equally to this work.

Conflict of Interests: None.

Ethical Approval: IR.SBMU.MSP.REC.1397.126

Funding/Support: None.

Informed Consent: Informed consent was obtained from the patients.

\section{References}

1. Vincent JL, Opal SM, Marshall JC, Tracey KJ. Sepsis definitions: time for change. Lancet. 2013;381(9868):774-5. doi: 10.1016/S0140-6736(12)618157. [PubMed: 23472921]. [PubMed Central: PMC4535310].

2. Rudd KE, Kissoon N, Limmathurotsakul D, Bory S, Mutahunga B, Seymour CW, et al. The global burden of sepsis: barriers and potential solutions. Crit Care. 2018;22(1):232. doi: 10.1186/s13054-018-2157-z. [PubMed: 30243300]. [PubMed Central: PMC6151187].

3. Seymour CW, Rea TD, Kahn JM, Walkey AJ, Yealy DM, Angus DC. Severe sepsis in pre-hospital emergency care: analysis of incidence, care, and outcome. Am J Respir Crit Care Med. 2012;186(12):1264-71. doi: 10.1164/rccm.201204-0713OC. [PubMed: 23087028]. [PubMed Central: PMC3622444].

4. Fleischmann C, Scherag A, Adhikari NK, Hartog CS, Tsaganos T, Schlattmann P, et al. Assessment of global incidence and mortality of hospital-treated sepsis. Current estimates and limitations. Am J Respir Crit Care Med. 2016;193(3):259-72. doi: 10.1164/rccm.201504-07810C. [PubMed: 26414292].

5. Rudd KE, Johnson SC, Agesa KM, Shackelford KA, Tsoi D, Kievlan DR, et al. Global, regional, and national sepsis incidence and mortality, 1990-2017: analysis for the Global Burden of Disease Study. Lancet. 2020;395(10219):200-11. doi: 10.1016/S0140-6736(19)32989-7. [PubMed: 31954465]. [PubMed Central: PMC6970225].

6. Rhodes A, Evans LE, Alhazzani W, Levy MM, Antonelli M, Ferrer $\mathrm{R}$, et al. Surviving sepsis campaign: International guidelines for management of sepsis and septic shock: 2016. Intensive Care Med. 2017;43(3):304-77. doi: 10.1007/s00134-017-4683-6. [PubMed: 28101605]. 
7. Seymour CW, Gesten F, Prescott HC, Friedrich ME, Iwashyna TJ, Phillips GS, et al. Time to treatment and mortality during mandated emergency care for sepsis. N Engl J Med. 2017;376(23):2235-44. doi: 10.1056/NEJMoa1703058. [PubMed: 28528569]. [PubMed Central: PMC5538258].

8. Liu VX, Fielding-Singh V, Greene JD, Baker JM, Iwashyna TJ, Bhattacharya J, et al. The timing of early antibiotics and hospital mortality in sepsis. Am J Respir Crit Care Med. 2017;196(7):856-63. doi: 10.1164/rccm.201609-18480C. [PubMed: 28345952]. [PubMed Central: PMC5649973].

9. Bikle D. Nonclassic actions of vitamin D. J Clin Endocrinol Metab. 2009;94(1):26-34. doi: 10.1210/jc.2008-1454. [PubMed: 18854395]. [PubMed Central: PMC2630868].

10. Holick MF. Vitamin D status: measurement, interpretation, and clinical application. Ann Epidemiol. 2009;19(2):73-8. doi: 10.1016/j.annepidem.2007.12.001. [PubMed: 18329892]. [PubMed Central: PMC2665033].

11. Hewison M. Vitamin D and innate and adaptive immunity. Vitam Horm. 2011;86:23-62. doi: 10.1016/B978-0-12-386960-9.00002-2. [PubMed: 21419266].

12. Hewison M. Antibacterial effects of vitamin D. Nat Rev Endocrinol. 2011;7(6):337-45. doi: 10.1038/nrendo.2010.226. [PubMed: 21263449].

13. Jeng L, Yamshchikov AV, Judd SE, Blumberg HM, Martin GS, Ziegler $\mathrm{TR}$, et al. Alterations in vitamin D status and anti-microbial peptide levels in patients in the intensive care unit with sepsis. J Transl Med. 2009;7:28. doi: 10.1186/1479-5876-7-28. [PubMed: 19389235]. [PubMed Central: PMC2684740].

14. Van den Berghe G, Van Roosbroeck D, Vanhove P, Wouters PJ, De Pourcq L, Bouillon R. Bone turnover in prolonged critical illness: effect of vitamin D. J Clin Endocrinol Metab. 2003;88(10):4623-32. doi: 10.1210/jc.2003-030358. [PubMed: 14557432].

15. Lee P, Eisman JA, Center JR. Vitamin D deficiency in critically ill patients. N Engl J Med. 2009;360(18):1912-4. doi:10.1056/NEJMc0809996. [PubMed: 19403914].

16. Lucidarme O, Messai E, Mazzoni T, Arcade M, du Cheyron D. Incidence and risk factors of vitamin D deficiency in critically ill patients: results from a prospective observational study. Intensive Care Med.2010;36(9):1609-11. doi:10.1007/s00134-010-1875-8. [PubMed: 20373095].

17. Matthews LR, Ahmed Y, Wilson KL, Griggs DD, Danner OK. Worsening severity of vitamin D deficiency is associated with increased length of stay, surgical intensive care unit cost, and mortality rate in surgical intensive care unit patients. Am J Surg. 2012;204(1):37-43. doi: 10.1016/j.amjsurg.2011.07.021. [PubMed: 22325335]. [PubMed Central: PMC3992708].

18. Braun AB, Litonjua AA, Moromizato T, Gibbons FK, Giovannucci E, Christopher KB. Association of low serum 25-hydroxyvitamin D levels and acute kidney injury in the critically ill. Crit Care Med. 2012;40(12):3170-9. doi: 10.1097/CCM.0b013e318260c928. [PubMed: 22975885].

19. Braun A, Chang D, Mahadevappa K, Gibbons FK, Liu Y, Giovannucci E, et al. Association of low serum 25-hydroxyvitamin D levels and mortality in the critically ill. Crit Care Med. 2011;39(4):671-7. doi: 10.1097/CCM.ob013e318206ccdf. [PubMed: 21242800]. [PubMed Central: PMC3448785].

20. Autier P, Gandini S. Vitamin D supplementation and total mortality: a meta-analysis of randomized controlled trials. Arch Intern Med. 2007;167(16):1730-7. doi: 10.1001/archinte.167.16.1730. [PubMed: 17846391].

21. Higgins DM, Wischmeyer PE, Queensland KM, Sillau SH, Sufit AJ, Heyland DK. Relationship of vitamin D deficiency to clinical outcomes in critically ill patients. J Parenter Enteral Nutr. 2012;36(6):713-20. doi: 10.1177/0148607112444449. [PubMed: 22523178].

22. Flynn L, Zimmerman LH, McNorton K, Dolman M, Tyburski J, Bay- lor A, et al. Effects of vitamin D deficiency in critically ill surgical patients. Am J Surg. 2012;203(3):379-82. discussion 382. doi: 10.1016/j.amjsurg.2011.09.012. [PubMed: 22206852].

23. Hashemipour S, Larijani B, Adibi H, Javadi E, Sedaghat M, Pajouhi M, et al. Vitamin D deficiency and causative factors in the population of Tehran. BMC Public Health. 2004;4:38. doi: 10.1186/1471-2458-4-38. [PubMed: 15327695]. [PubMed Central: PMC517720].

24. Shojaei M, Sabzeghabaei A, Valaei Barhagh H, Soltani S. The correlation between serum level of vitamin $\mathrm{d}$ and outcome of sepsis patients; A cross-sectional study. Arch Acad Emerg Med. 2019;7(1). e1. [PubMed: 30847436]. [PubMed Central: PMC6377223].

25. Nguyen HB, Eshete B, Lau KH, Sai A, Villarin M, Baylink D. Serum 1,25-dihydroxyvitamin D: an outcome prognosticator in human sepsis. PLoS One. 2013;8(5). e64348. doi: 10.1371/journal.pone.0064348. [PubMed: 23741318]. [PubMed Central: PMC3669325].

26. Moromizato T, Litonjua AA, Braun AB, Gibbons FK, Giovannucci E, Christopher KB. Association of low serum 25-hydroxyvitamin D levels and sepsis in the critically ill. Crit Care Med. 2014;42(1):97-107. doi: 10.1097/CCM.ob013e31829eb7af. [PubMed: 23982028].

27. Alves FS, Freitas FG, Bafi AT, Azevedo LC, Machado FR. Serum concentrations of vitamin D and organ dysfunction in patients with severe sepsis and septic shock. Rev Bras Ter Intensiva. 2015;27(4):376-82. doi 10.5935/0103-507X.20150063. [PubMed: 26761476]. [PubMed Central: PMC4738824].

28. Rech MA, Hunsaker T, Rodriguez J. Deficiency in 25-hydroxyvitamin D and 30-day mortality in patients with severe sepsis and septic shock Am J Crit Care. 2014;23(5):e72-9. doi: 10.4037/ajcc2014723. [PubMed: 25179041].

29. Arnson Y, Gringauz I, Itzhaky D, Amital H. Vitamin D deficiency is associated with poor outcomes and increased mortality in severely ill patients. QJM. 2012;105(7):633-9. doi: 10.1093/qjmed/hcs014. [PubMed: 22331959].

30. Deluca HF, Cantorna MT. Vitamin D: its role and uses in immunology. FASEB J. 2001;15(14):2579-85. doi: 10.1096/fj.01-0433rev. [PubMed 11726533].

31. Gysemans CA, Cardozo AK, Callewaert H, Giulietti A, Hulshagen L, Bouillon R, et al. 1,25-Dihydroxyvitamin D3 modulates expression of chemokines and cytokines in pancreatic islets: implications for prevention of diabetes in nonobese diabetic mice. Endocrinology. 2005;146(4):1956-64. doi: 10.1210/en.2004-1322. [PubMed: 15637289].

32. Mora JR, Iwata M, von Andrian UH. Vitamin effects on the immune system: vitamins A and D take centre stage. Nat Rev Immunol. 2008;8(9):685-98. doi: 10.1038/nri2378. [PubMed: 19172691]. [PubMed Central: PMC2906676].

33. Nursyam EW, Amin Z, Rumende CM. The effect of vitamin D as supplementary treatment in patients with moderately advanced pulmonary tuberculous lesion. Acta Med Indones. 2006;38(1):3-5 [PubMed: 16479024].

34. Cannell JJ, Vieth R, Umhau JC, Holick MF, Grant WB, Madronich S, et al. Epidemic influenza and vitamin D. Epidemiol Infect. 2006;134(6):112940. doi: 10.1017/S0950268806007175. [PubMed: 16959053]. [PubMed Central: PMC2870528].

35. White AN, Ng V, Spain CV, Johnson CC, Kinlin LM, Fisman DN. Let the sun shine in: effects of ultraviolet radiation on invasive pneumococcal disease risk in Philadelphia, Pennsylvania. BMC Infect Dis. 2009;9:196. doi: 10.1186/1471-2334-9-196. [PubMed: 19961583]. [PubMed Central: PMC2797517].

36. Board ASPEN. Guidelines for the use of parenteral and enteral nutrition in adult and pediatric patients. $J$ Parenter Enteral Nutr 2016;17(4_suppl):1SA-52SA. doi:10.1177/014860719301700401.

37. Heaney RP, Davies KM, Chen TC, Holick MF, Barger-Lux MJ. Human serum 25-hydroxycholecalciferol response to extended oral dosing with cholecalciferol. Am J Clin Nutr. 2003;77(1):204-10. doi: 10.1093/ajcn/77.1.204. [PubMed: 12499343]. 